\title{
Control of cleavage and further development in vitro in reconstituted two-cell mouse embryos
}

\author{
L. C. Smith* and I. Wilmut \\ AFRC Roslin Institute (Edinburgh), Roslin, Midlothian EH25 9PS, UK
}

\begin{abstract}
Nuclear-cytoplasmic interactions during the second cell cycle of mouse embryos were examined by assessing the timing of cleavage in reconstituted two-cell embryos and their ability to develop further to the blastocyst stage in vitro. Nuclear transplantations were performed either within or across the cell cycle and at different stages of the cell cycle to assess the effect of 'asynchrony' on development. In most cases, cleavage occurred at an intermediate time between nuclear and cytoplasmic controls indicating an interaction in their mechanisms for controlling the timing of cleavage. Early nuclei extended the cleavage timing of late cytoplasm for a short period, possibly to allow for completion of DNA synthesis, while early cytoplasm delayed the expected cleavage time of late nuclei, possibly to enable proper maturation of cytoplasmic components. However, a block of cleavage was observed in most across cell cycle transplantations and also when fusing early two-cell karyoplasts to enucleated late two-cell blastomeres. It is suggested that this incompatibility is caused by major changes in the transcriptional status of donor and recipient cells. Although the development of reconstituted embryos to the blastocyst stage was clearly affected by cell cycle 'asynchrony' in within cell cycle transplantations, independent effects of cytoplast stage and, to a lesser extent, of karyoplast cell cycle stage were predominant in transplantations using eight-cell karyoplasts.
\end{abstract}

\section{Introduction}

During early cleavage stages, the mouse embryo experiences major changes in the biochemical components of both nucleus and cytoplasm. Although the events that take place during the first cell cycle after fertilization have been shown to be under a post-transcriptionally controlled programme, transcriptional activation by the embryonic genome at the initial stages of the second cell cycle and the appearance of translation products in the cytoplasm are known to be necessary for controlling the following two cleavages to the eight-cell stage and the accompanying morphological alterations to the cellular architecture during the fourth cell cycle (Flach et al., 1982; McLachlin et al., 1983; Bolton et al., 1984). These reports therefore indicate that, in contrast to the first cell cycle, nuclear activity plays an active role in providing cell cycle regulatory factors during the second cell cycle to control mitosis and further development and differentiation.

Studies using nuclear transplantation in mouse embryos have shown that the ability of a blastomere nucleus to support development to the blastocyst stage in vitro and to term depends on the stage of the recipient cytoplasm to which it is fused. Recipient cytoplasts from one- and two-cell embryos were used and it was shown that, while nuclei from four- and

\footnotetext{
*Present address and address for correspondence: Centre de recherche en reproduction animale, Faculté de médecine vétérinaire, Université de Montréal, CP 5000, Saint-Hyacinthe, Québec, Canada, J2S 7C6.

Revised manuscript received 2 July 1993.
}

eight-cell blastomeres could support development to the blastocyst stage (Robl et al., 1986) and, on some occasions, to term (Tsunoda et al., 1987) when transferred to two-cell stage cytoplasm, no development could be obtained after transplantations to the cytoplasm of one-cell enucleated zygotes (McGrath and Solter, 1984; Surani et al., 1987; Smith et al., 1988). However, the ability of two-cell cytoplasm to support normal development is limited to a few exceptions since most reconstituted embryos stop developing during the preimplantation stages. More recent studies have shown that most blastocysts obtained lack a normal inner cell mass and do not produce pregnancies after transfer to suitable recipients (Kono and Tsunoda, 1989).

Effects caused by the asynchrony between the stage of the cell cycle of donor nuclei and recipient cytoplasm are known to influence subsequent development in Amphibia (Von Beroldingen, 1981) and mice (Smith et al., 1988; Kono et al., 1992). In mouse zygotes, although development to blastocyst was clearly influenced by 'synchrony' in transplantations within the first cell cycle, across cell cycle transplantations using nuclei from early, mid- and late two-cell blastomeres produced effects caused independently by the donor nucleus and recipient cytoplasm. Further analysis of the timing of cleavage in 'asynchronous' nuclear transplantations within the cell cycle indicated a cytoplasmic control for the first mitotic division (Smith et al., 1990). However, transplantations using nuclei from two-cell blastomeres showed alterations in cytoplasmic cleavage timing expressed either by a short extension of 
mitosis or by indefinite mitotic arrest, which indicated an active role for the two-cell nucleus for controlling cleavage and further development.

The following studies have examined the effects of 'synchrony' in within and across cell cycle nuclear transplantations to the cytoplasm of two-cell blastomeres. Assessment of the timing of cleavage of two-cell nuclear transplantation within and across the cell cycle have enabled a clearer understanding of nucleocytoplasmic interactions during the second cell cycle and the control of cleavage and development to the blastocyst stage.

\section{Materials and Methods}

\section{Embryos}

Female $\mathrm{F}_{1}$ hybrid mice $(\mathrm{C} 57 \mathrm{~B} 1 / 6 \times \mathrm{CBA} / \mathrm{Ca})$, averaging 5-6 weeks of age, were superovulated to provide embryos as described by Smith et al. (1990). Gonadotrophin injections were timed accordingly for each experiment to provide embryos at several stages of embryonic development. In the studies within the cell cycle (Expt 1 and 2), early two-cell embryos (E2) were harvested at $30 \mathrm{~h}$ after hCG and manipulated between 1 and $1.5 \mathrm{~h}$ after first cleavage, mid-two-cell stage embryos (M2) harvested at 38-42 $\mathrm{h}$ after hCG and the late two-cell stage embryos (L2) were harvested and manipulated between 44 and $48 \mathrm{~h}$ after hCG. In the first experiment of the across cell cycle studies (Expt 3), pronuclear embryos were harvested and manipulated between 24 and $28 \mathrm{~h}$ after hCG, two-cell embryos between 38 and $42 \mathrm{~h}$ after hCG, four-cell embryos between $5 \mathrm{I}$ and $55 \mathrm{~h}$ after hCG and eight-cell embryos between 62 and $66 \mathrm{~h}$ after hCG injections. In the second experiments of this series (Expt 4), E2 and L2 control and recipient enucleated embryos were obtained and manipulated as described for the within cell cycle studies, while the early eight-cell embryos (E8) were harvested and manipulated between 61 and $64 \mathrm{~h}$ after hCG and the late eight-cell stages (L8) between 67 and $70 \mathrm{~h}$ after hCG injections. After hCG injection, females were paired with hybrid $\mathrm{F}_{1}$ males $(\mathrm{MF} 1 \times \mathrm{SWR})$ and inspected the following morning for copulation plugs. Embryos were flushed from the oviduct or uterus at approximately $1 \mathrm{~h}$ before microsurgery, using Hepes-buffered medium (M2: Quinn et al., 1982), and placed in bicarbonate-buffered Medium $16+0.4 \% \quad(\mathrm{w} / \mathrm{v})$ BSA (M16 + BSA; Whittingham, 1971) until microsurgery.

\section{Microsurgery and controls}

Medium preparation for microsurgical procedures was as described by Smith et al. (1990). Blastomere enucleations were performed by removing the nuclei (karyoplasts) from both blastomeres of the recipient two-cell embryos. Nuclear transplantation was performed by transferring a single karyoplast from a different embryo together with a small amount of an inactivated Sendai virus solution into the perivitelline space (Giles and Ruddle, 1983). Karyoplasts were positioned in such a way as to provide membrane contact with a single blastomere. Only those embryos in which the karyoplast had fused to a single blastomere were used for experimentation.
Three kinds of controls were provided in each experimental batch. First, two-cell embryos were placed into Medium 16 and cultured immediately after collection, which allowed an assessment of general culture conditions. Second, two-cell embryos were placed in the manipulation medium with cytoskeletal inhibitors for a period similar to the nuclear transplanted group before washing in $\mathrm{M} 2$ and culture in Medium 16. This control enabled assessment of the effects caused by exposure to cytoskeletal inhibitors and room temperature conditions. Third, the nucleus of one of the blastomeres was removed, leaving a single nucleated blastomere to support development which was compared directly to the nuclear-transplanted embryos.

\section{Embryo culture and assessment}

Nuclear transplanted and control embryos were placed in $40 \mu \mathrm{l}$ drops of Medium 16 plus BSA covered with paraffin oil (BDH, UK) which had been equilibrated in Medium 16. Embryos were then incubated at $37.5^{\circ} \mathrm{C}$ in a humidified atmosphere of $5 \% \mathrm{CO}_{2}$ immediately after manipulations. Time of cleavage was assessed by counting the number of embryos cleaved at any particular time. This was performed at approximately $8,16,24$ and $40 \mathrm{~h}$ after manipulations in all embryos except for Expt 3 in the across cell cycle studies which were not assessed for cleavage time. Cleavage assessment was performed by removing the culture dishes from the incubator and placing them on the pre-heated stage of a dissecting microscope at $37^{\circ} \mathrm{C}$ as quickly as possible to avoid major fluctuations in temperature. Non-enucleated two-cell control embryos were identified as cleaved when at least one of the blastomeres had cleaved (three- or four-cell stage). To allow for differences in recipient cytoplasm, developmental timing of manipulated and control embryos having E2 recipient cytoplasm were assessed at $86 \mathrm{~h}$ after manipulation, whereas those using M2 and L2 treated and control groups were assessed at $72 \mathrm{~h}$ after manipulations. In the latter groups, no difference in the percentage of blastocysts was noticed between assessments at 72 and $86 \mathrm{~h}$. Data on the number of control and treated embryos developing to blastocyst stage and on their cleavage percentages were analysed using Fisher's exact test for twoway contingency tables.

\section{Results}

An indication of the relationship between the development stages at which embryos underwent microsurgery and known cellular and biochemical events during the initial cleavage stages is shown (Fig. I).

Experiment 1. This experiment was performed to determine the appropriate controls. No significant difference in cleavage timing $(P>0.5)$ or blastocyst development $(P>0.05)$ was observed between control two-cell embryos (early and late groups) placed either immediately in culture or exposed to the microsurgical medium for a period similar to nuclear transplanted embryos. However, comparisons between nonenucleated and demi-enucleated controls showed significant differences in both cleavage timing and development to 


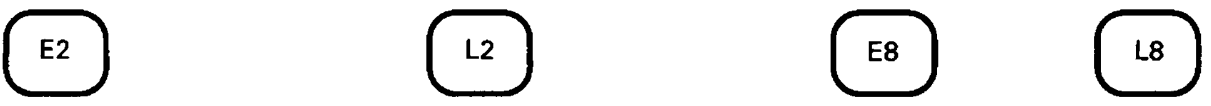

Embryonic stages

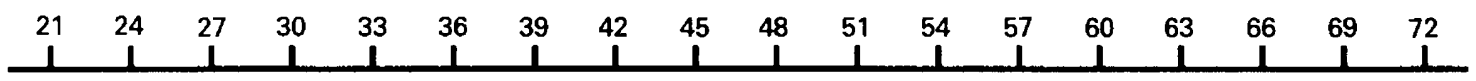

Time after hCG (h)

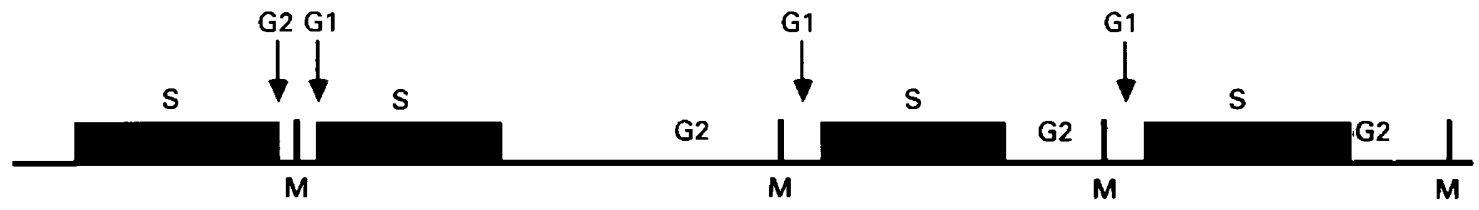

Cellular events

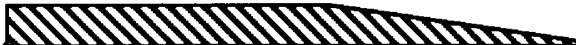

Maternal mRNA

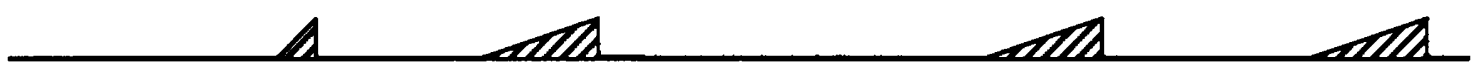

Zygotic mRNA

Fig. 1. Molecular and cellular events during the first, second, third and fourth cleavage cell cycles. Relationship with the time (embryonic stages) of transplantation to enucleated two-cell blastomeres (Adapted from Bolton et al., 1984; and Smith and Johnson, 1986). E2: early two-cell stage embryos; L2: late two-cell stage embryos; E8: early eight-cell stage embryos; L8: late eight-cell stage embryos.

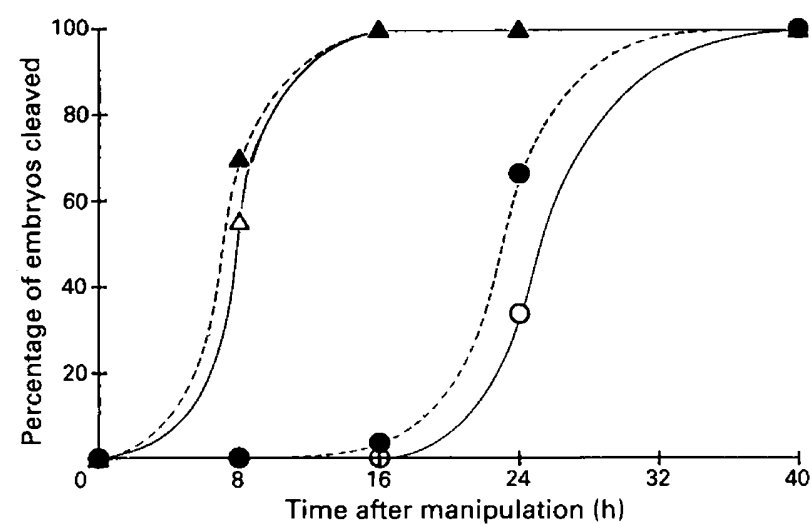

Fig. 2. Cleavage proportions per unit time of demi-enucleated and non-enucleated early (E2) and late (L2) control two-cell embryos exposed to the micromanipulation environment for a period similar to that used in the reconstitution of two-cell embryos. (O) demienucleated E2 $(n=65)$; $(\bigcirc)$ non-enucleated E2 $(n=413) ;(\triangle)$ demienucleated L2 $(n=78) ;(\boldsymbol{\Delta})$ non-enucleated L2 $(n=323)$.

blastocyst. Although there was no difference in the timing of cleavage in the L2 control groups, significantly more E2 control embryos had cleaved at $24 \mathrm{~h}$ after manipulation in the nonenucleated than in the demi-enucleated control group $(P<0.05)$ (Fig. 2). Although there was no difference between the percentage of embryos that developed to the blastocyst stage in the L2 control groups ( $94.4 \%$ versus $94.9 \% P>0.05)$, significantly more control M2 $(97.5$ versus $89.4 \% P<0.05)$ and
E2 (96.1 versus $86.2 \% \quad P<0.01$ ) embryos developed to the blastocyst stage when non-enucleated than when one of the blastomeres had been enucleated (demi-enucleated) (Fig. 3). Together, these results indicate that the demi-enucleated group is the most appropriate control group for comparison with reconstituted two-cell embryos in which a nucleus is fused to a single blastomere, while the other blastomere remains enucleated. They also indicate that embryos composed of a single nucleated two-cell blastomere are increasingly more capable of developing into blastocysts when recovered and manipulated at later stages of the second cell cycle.

\section{Transplantations within the second cell cycle}

Experiment 2. In this experiment, controls and reconstituted embryos derived from nuclear transplantations between twocell embryos at similar (synchronous) and opposite (asynchronous) extremes of the second cell cycle were compared with demi-enucleated controls.

Synchronous transplantations. In comparison with demienucleated controls, neither the time of cleavage $(P>0.05$; Fig. 4) nor the ability to develop to blastocyst $(P>0.05$; Table 1$)$ was significantly affected by synchronous transplantations between either early or late two-cell embryos. This demonstrates that the technique of nuclear transplantation itself had no effect on the development of manipulated two-cell embryos as determined in these experiments. 

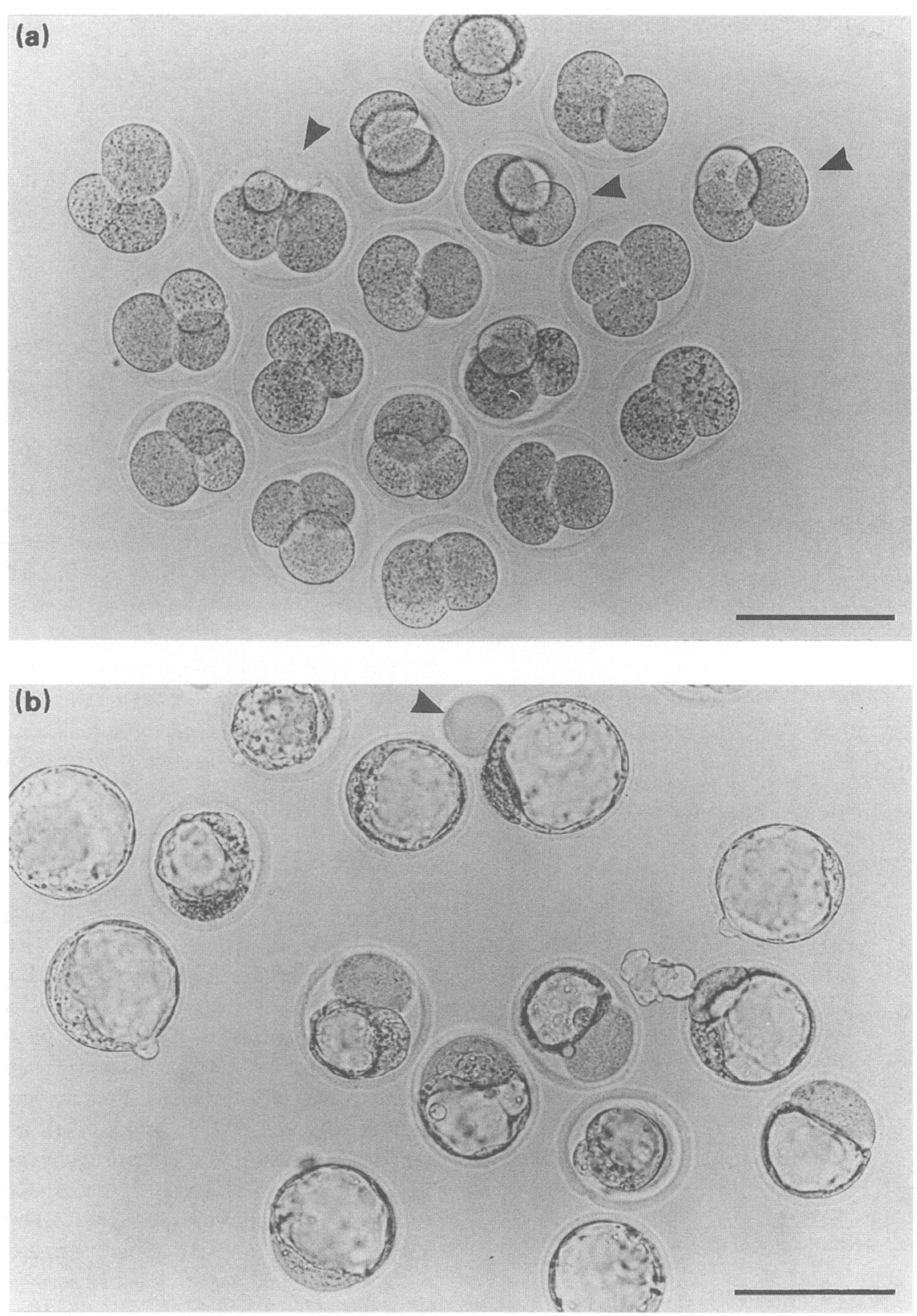

Fig. 3. Reconstituted two-cell embryos derived from the fusion of two-cell karyoplasts to a single blastomere of an enucleated two-cell embryo. (a) At $16 \mathrm{~h}$ after manipulation only the blastomeres that have fused to karyoplast will cleave to the third cell cycle (three-cell), while embryos with non-fused karyoplasts remain at the two-cell stage (arrowheads); (b) at $72 \mathrm{~h}$ after manipulation most reconstituted embryos have developed to the blastocyst stage. In most cases, blastocyst expansion causes the expulsion of the enucleated blastomere from the zona pellucida (arrowhead). Scale bar represents $100 \mu \mathrm{m}$.

Asynchronous transplantations. There were significant effects of asynchronous transplantations upon the time of cleavage, but the effect depended upon the particular combination of donor and recipient cell stage (Fig. 4). After fusion of a late two-cell karyoplast with early two-cell cytoplasm, all of the embryos in this asynchronous group cleaved. Cleavage occurred at an intermediate time between that of early and late control embryos and at a time which was significantly different from them both $(P<0.01)$. By contrast, when an early two-cell nucleus was transferred to a late two-cell cytoplast, only 31.7\% of the embryos cleaved. Among the embryos that did cleave (13 of 41 embryos), the pattern of cleavage was similar to that in late controls, with $15.4,76.9$ and $100 \%$ of the embryos dividing by 8,16 and 24 h, respectively, compared with 65.9 , 100 and $100 \%$ in the late controls at these times. These observations suggest that in addition to causing a block to 


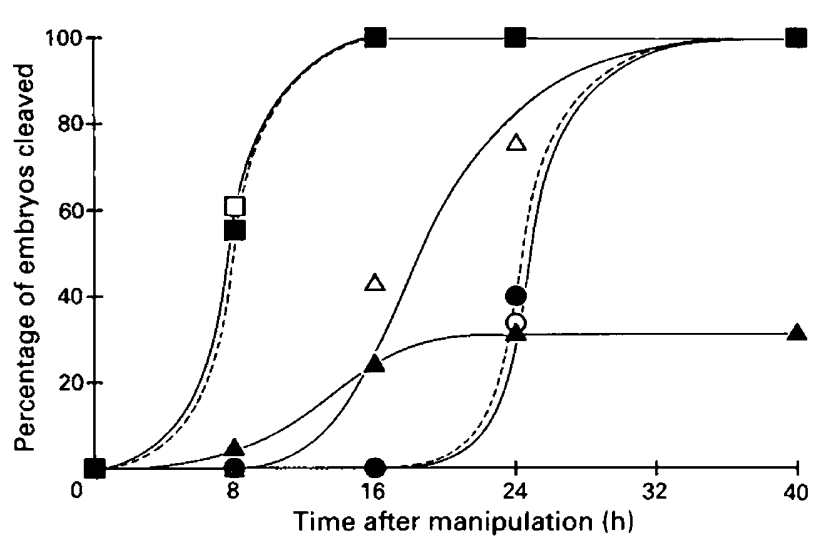

Fig. 4. Cleavage proportions per unit time of control and within cell cycle 'synchronously' and 'asynchronously' reconstituted two-cell embryos derived from the transplantation of karyoplasts and cytoplasts at early (E2) and late (L2) stages of the second cell cycle. (O) control E2 $(n=65) ;(\bigcirc)$ E2 $\rightarrow$ E2 $(n=50) ;(\triangle)$ L2 $\rightarrow$ E2 $(n=37) ;(\mathbf{\Delta})$ $\mathrm{E} 2 \rightarrow \mathrm{L} 2(n=41) ;(\square) \mathrm{L} 2 \rightarrow \mathrm{L} 2(n=51)$; (口) control L2 $(n=78)$.

cleavage in the majority of embryos, the effect of transplanting an early two-cell nucleus to a late two-cell cytoplast was to delay cleavage by approximately $6 \mathrm{~h}$.

After asynchronous transfer, the proportion of manipulated embryos that developed to the blastocyst stage was significantly lower than in the control embryos or in reconstituted embryos produced by synchronous transfer $(P<0.01)$. In addition, there was a significant difference between the two asynchronous groups $(P<0.01)$. An embryo produced by transplantation of an early two-cell nucleus to a late two-cell cytoplast was less able to support development to the blastocyst stage than was one produced by transplantation of a late two-cell nucleus to an early two-cell cytoplast. When considering only those embryos that cleaved, a similar proportion of the embryos could form blastocysts, suggesting that failure to cleave was the cause of most of the difference between the two asynchronous groups. The proportion of embryos that cleaved that could form blastocysts was significantly lower than the proportion in the control groups $(P<0.05)$.

\section{Across cell cycle transplantations}

Experiment 3. This experiment was designed to assess the ability of blastomere nuclei from different stages to support in vitro development to the blastocyst stage after transplantation to single enucleated two-cell blastomeres. The proportion of embryos reconstituted with two-cell karyoplasts that developed to blastocysts was similar to that of demi-enucleated controls $(P>0.05)$. Among reconstituted embryos derived by the fusion of single enucleated two-cell blastomeres to four-cell karyoplasts, $90 \%$ developed to blastocyst, a similar percentage to those derived from two-cell karyoplasts and to the manipulated controls $(93.3 \%$ versus $89.4 \% P>0.05)$, which indicates that there are no noticeable changes in potential, in nucleocytoplasmic compatibility between the second and the third cell cycle or changes in both. However, when using eight-cell karyoplasts, there was a substantial decline in the percentage reaching the blastocyst stage $(50 \% P<0.01)$. Embryos recon-

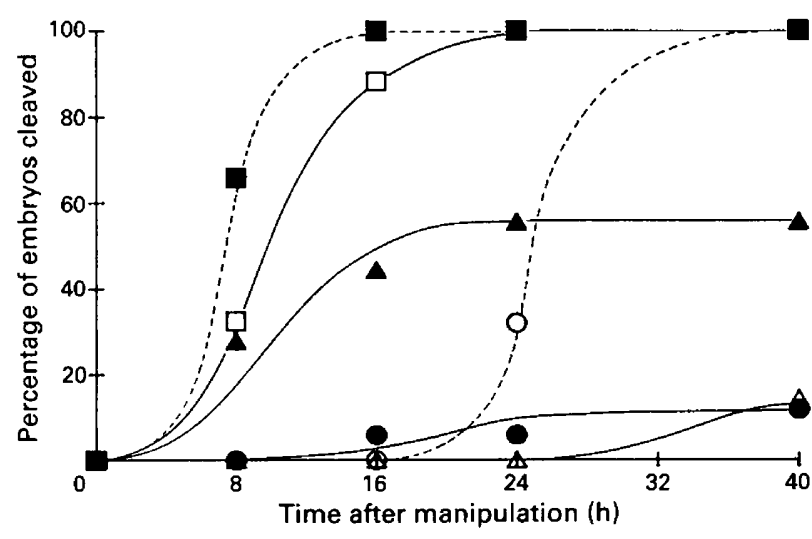

Fig. 5. Cleavage proportions per unit time of control and across cell cycle reconstituted two-cell embryos derived from early (E8) and late (L8) eight-cell karyoplasts to enucleated blastomeres from early (E2) and late (L2) two-cell embryos. (O) control E2 $(n=25) ;(O)$ E8 $\rightarrow$ E2 $(n=17) ;(\triangle)$ L8 $\rightarrow$ E2 $(n=21) ;(\Delta)$ L8 $\rightarrow$ L2 $(n=18) ;(\square)$ E8 $\rightarrow$ L2 $(n=34) ;(\square)$ control L2 $(n=44)$.

stituted from fusions between pronuclear karyoplasts and twocell blastomeres were not only unable to develop into blastocysts, but also arrested mitotic division completely. These reconstituted embryos remained as two-cell blastomeres until fragmentation occurred owing to degeneration a few days later.

Experiment 4. This experiment was designed to examine more closely the effect of cell cycle stage when transplanting a nucleus from an eight-cell embryo to one cell of a two-cell embryo. The proportion of reconstituted embryos that cleaved and the time of cleavage were affected by the stage of the cell cycle of both the donor and recipient cell (Fig. 5). All of the embryos cleaved in only one of the four groups: that in which an early eight-cell karyoplast was fused with a late two-cell cytoplasm. In this group, cleavage occurred at a time intermediate between that of early and late control demi-enucleated two-cell embryos and at a time that was significantly different from them both $(P<0.05)$. The extension of the cycle by the early eight-cell nucleus was equivalent to approximately $4 \mathrm{~h}$. After transplantation of a late eight-cell nucleus to a late two-cell cytoplast, only $56 \%$ of the embryos cleaved. Among those embryos that did divide, the time of cleavage was not significantly different from the late two-cell control at any time $(P>0.05)$. When the recipient cytoplast was derived from an early two-cell embryo, very few of the reconstituted embryos cleaved with either an early eight-cell nucleus $(11.8 \%)$ or a late eight-cell nucleus (14.3\%). Although the number of embryos is too small for statistical analysis, it appeared that the early eight-cell group began to divide earlier than the late eight-cell group.

The proportion of reconstituted embryos that reached the blastocyst stage was influenced by the stage of the cycle of both donor eight-cell and the recipient two-cell embryo (Table 2). Only a small proportion of reconstituted embryos developed to blastocysts, significantly fewer than in demi-enucleated controls $(P<0.01)$. No embryos formed blastocysts following transplantation to an early two-cell karyoplast. A higher proportion of reconstituted embryos developed to the blastocyst stage when the karyoplast was derived from an early 
Table 1. Effect of cell-cycle-stage synchrony between two-cell donor karyoplasts and recipient cytoplasts on the development to blastocyst in vitro of reconstituted embryos, compared with development of control two-cell embryos from which one nucleus had been removed

\begin{tabular}{lcccc}
\hline Cytoplast stage & Demi-enucleated control (\%) & Synchronous groups (\%) & Asynchronous groups (\%) & Asynchronous cleaving* (\%) \\
\hline Early two-cell & $86.2^{\mathrm{a}}$ & $92.0^{\mathrm{a}}$ & $64.9^{\mathrm{b}}$ & $64.9^{\mathrm{b}}$ \\
$n$ & 65 & 50 & 37 & 37 \\
Late two-cell & $94.9^{\mathrm{a}}$ & $92.8^{\mathrm{a}}$ & $19.5^{\mathrm{c}}$ & $62.5^{\mathrm{b}}$ \\
$n$ & 78 & 42 & 41 & 13 \\
Totals & 90.9 & 92.4 & 41.0 & 64.0 \\
$n$ & 143 & 92 & 78 & 50 \\
\hline
\end{tabular}

$n$ : numbers of embryos in each group.

*Proportions using embryos that cleaved beyond the second cell cycle.

${ }^{\text {abc }}$ Differ at a $1 \%$ level of significance.

Table 2. Effect of cell-cycle stage upon development to blastocyst of reconstituted embryos derived by fusion of eight-cell donor and two-cell recipient cytoplasts, compared with development of control two-cell embryos from which one nucleus had been removed

\begin{tabular}{|c|c|c|c|c|}
\hline \multirow[b]{2}{*}{ Cytoplast stage } & \multirow[b]{2}{*}{ Demi-enucleated control (\%) } & \multicolumn{2}{|c|}{ Stage of karyoplast } & \multirow[b]{2}{*}{ Cytoplast totals } \\
\hline & & Early eight-cell (\%) & Late eight-cell (\%) & \\
\hline Early two-cell & $84.0^{\mathrm{a}}$ & none $^{\mathrm{c}}$ & none ${ }^{c}$ & none \\
\hline$n$ & 25 & 17 & 21 & 38 \\
\hline Late two-cell & $97.8^{\mathrm{a}}$ & $26.5^{b}$ & $5.6^{\mathrm{bc}}$ & 19.2 \\
\hline$n$ & 44 & 34 & 18 & 52 \\
\hline Karyoplast totals & 92.8 & 17.6 & 2.6 & 11.1 \\
\hline$n$ & 69 & 51 & 39 & 90 \\
\hline
\end{tabular}

$n$ : number of embryos in each group.

${ }^{\text {abc }}$ Differ significantly $(P<0.05)$.

eight-cell rather than a late eight-cell nucleus $(P<0.05)$. In the most successful combination, nine of 34 embryos formed blastocysts (26.5\%) following transplantation of an early eightcell nucleus to a late two-cell cytoplast.

\section{Discussion}

These results show that the ability of a reconstituted embryo, derived by transplantation of a nucleus to a single blastomere of a two-cell embryo, to divide and develop to the blastocyst stage depends upon the stage of the cell cycle of both nucleus and cytoplasm at the time of fusion. The effect of cell cycle when transplantation was between two embryos at the twocell stage was different from that when nuclei were transplanted from eight-cell embryos to two-cell embryos. When the embryos were both at the two-cell stage, nuclear transplantation had no effect upon the ability to develop to the blastocyst stage provided that donor and recipient embryos were at the same stage of the cell cycle. After transplantation from eight-cell to two-cell embryos this effect of synchrony of the cell cycle was not apparent. By contrast, these transplantations were mostly affected by the stage of the recipient cytoplast (late two-cell were best), with a smaller effect of karyoplast (early eight-cell was best). Overall, these findings are similar to those reported when one-cell embryos were the recipient cells (Smith et al., 1988).

Some of the effects of embryo stage (Expt 3) and cell cycle stage (Expts 2 and 4) may be accounted for by allowing for changes in the pattern of transcription during this period of development. A concept has been advanced of domains of development within which the patterns of protein production and degradation are similar. There is evidence that there are three domains during this period of development in mice: the first domain lasting from fertilization to the initiation of transcription and destruction of most maternal mRNA during the two-cell stage, a second domain lasting from then until the changes in the eight-cell embryo which are associated with compaction and the third domain beginning at this time (Johnson et al., 1984). It is suggested that transplantation of nuclei between embryos in the same domain of development is more likely to succeed than that between embryos in different domains, because in the latter case the nuclei are exposed to unusual cytoplasmic environments in which development may become abnormal. This suggestion is compatible with the results of many nuclear transfer experiments with one- and two-cell mouse recipients (McGrath and Solter, 1984; Robl et al., 1986; Smith et al., 1988; Kono and Tsunoda, 1989). Among 
the eight combinations of donor and recipient embryo stage that were compared in these experiments, the greatest similarity occurred when synchronous transfers were made between two-cell embryos. In these cases all the embryos divided and the great majority formed blastocysts. By contrast, the greatest difference in development was created when nuclei were transplanted from late eight-cell embryos (in the third domain) to early two-cell embryos, in the first. In this group very few embryos cleaved and none formed blastocysts. In the other combinations the intermediate levels of development may be associated with differences in the extent of variation in the pattern of transcription between donor and recipient cells.

There is a need for the mechanisms that regulate cell division to be re-established following nuclear transplantation and there is evidence that the time and ability of the reconstituted embryo to undergo cell division is influenced by both the nucleus and the cytoplasm. Early nuclei from two-cell embryos extended the cycle by approximately $4-6 \mathrm{~h}$ following transfer to late cytoplasts. A similar period of extension was observed after transplantation of nuclei from early stages of the first or second cell cycle to cytoplast derived from late one-cell zygotes (Smith et al., 1990). This interval is similar to the estimated time of $4-7 \mathrm{~h}$ required for DNA replication in cleavage stage embryos (Smith and Johnson, 1986). It seems likely that, as reported for somatic cell hybrids, this short delay in cleavage is required for the completion of DNA synthesis before mitosis (Rao and Johnson, 1970; Rao et al., 1975).

In some treatments, only a minority of the embryos divided, whereas in others almost all of the embryos completed the first division, but were unable to reach the blastocyst stage. The immediate incompatibility that causes a complete block to cleavage was observed most often following transplantation between embryos at different cell cycles (e.g. early eight-cell to early two-cell embryos), but was occasionally seen after transplantation between two-cell embryos, as in fusion between early two-cell karyoplasts and late cytoplasts. Although the reason for this complete incompatibility is not known, the fact that failure occurred at different stages of development suggests that a number of mechanisms may be involved. One possible explanation is that a substantial proportion are unable to cleave because of chromosome pulverisation (Dyban et al., 1988).

It is not possible to distinguish between the effects of changes in the pattern of transcription and those of cell cycle stage in the present experiments, as it is possible that there is a change in the pattern of transcription within a cell cycle. Nuclei from teratocarcinoma cells have been fused to mouse oocytes resulting mostly in abnormal cleavage and arrest during early cleavage divisions (Modlinski et al., 1990). A definitive experiment must await the development of a procedure for transplantation of nuclei from stable cell lines, such as embryonic stem cell lines. Only in such a situation will it be possible to define clearly the effect of cell cycle stage.

As a nucleus transplanted from a different stage of the cell cycle could modify the time of cleavage when the cytoplast was from either early or late in the cell cycle (Expt 2), it is not clear why cytoplasts from later stages in the cell cycle are better able to support development of reconstituted embryos (Expt 4). This difference may be due to the fact that later cytoplasm is more mature and does not require a competent nucleus for division (Bolton et al., 1984). During division, the breakdown of the nuclear membrane may allow interaction of the chromatin with cytoplasmic factors able to reprogramme gene expression. However, an early cytoplasm would require a competent nucleus to produce the specific transcripts necessary for cleavage and a nucleus from a different cell cycle would not be able to provide stage-specific messages. Further research into the molecular regulation of early development will provide a better understanding of the effects of these interactions of DNA synthesis and transcription.

\section{References}

Bolton VN, Oades PJ and Johnson MH (1984) The relationship between cleavage, DNA replication and gene expression in the mouse two-cell embryo Journal of Embryology and Experimental Morphology 79 139-163

Dyban AP, Lee K, O'Neill GT, Speirs S and Kaufman MH (1988) Cytogenetic study of silver staining NOR in 8-cell stage mouse blastomeres fused to 1-cell stage embryos Development 104 453-463

Flach G, Johnson MH, Braude PR, Taylor RAS and Bolton VN (1982) The transition from maternal to embryonic control in the two-cell mouse embryo EMBO Journal 1 681-686

Giles RE and Ruddle FH (1983) Production of Sendai virus for cell fusion In Vitro 9 103-107

Johnson MH, McConnell J and VanBlerkom J (1984) Programmed development in the mouse embryo Journal of Embryology and Experimental Morphology 83 197-231

Kono T and Tsunoda Y (1989) Development of single blastomeres from fourand eight-cell mouse embryos fused into the enucleated half of a two-cell embryo Gamete Research 22 427-434

Kono T, Kwon OY, Watanabe T and Nakahara T (1992) Development of mouse enucleated oocytes receiving a nucleus from different stages of the second cell cycle Journal of Reproduction and Fertility 94 481-487

McGrath J and Solter D (1984) Inability of mouse blastomere nuclei transferred to enucleated zygotes to support development in vitro Science 226 13171319

McLachlin JR, Cavaney S and Kidder GM (1983) Control of gap junction formation in early mouse embryos Developmental Biology 98 155-164

Modlinski JA, Gerhauser D, Lioi B, Winking H and Illmensee K (1990) Nuclear transfer from teratocarcinoma cells into mouse oocytes and eggs Development 108 337-348

Quinn P, Barros C and Whittingham DG (1982) Preservation of hamster oocytes to assay the fertilizing capacity of human spermatozoa Journal of Reproduction and Fertility 66 161-168

Rao PN and Johnson RT (1960) Mammalian cell fusion: studies on the regulation of DNA synthesis and mitosis Nature 225 159-164

Rao PN, Hittleman WN and Wilson BA (1975) Mammalian cell fusion: VI, regulation of mitosis in binucleate HeLa cells Experimental Cell Research 90 $40-46$

Robl JM, Gilligan B, Critser ES and First NL (1986) Nuclear transplantation in mouse embryos: assessment of recipient cell stage Biology of Reproduction $\mathbf{3 4}$ 733-739

Smith LC, Wilmut I and Hunter RHF (1988) Influence of cell cycle stage at nuclear transplantation on the development in vitro of mouse embryos Journal of Reproduction and Fertility $84619-624$

Smith LC, Wilmut I and West JD (1990) Control of first cleavage in single-cell reconstituted mouse embryos Journal of Reproduction and Fertility $\mathbf{8 8} 655$ 663

Smith RKW and Johnson MH (1986) Analysis of the third and fourth cell cycles of mouse early development Journal of Reproduction and Fertility 76 393-399

Surani MAH, Barton SC and Norris ML (1987) Experimental reconstruction of mouse eggs and embryos: an analysis of mammalian development Biology of Reproduction 36 1-16

Tsunoda Y, Yasui T, Shioda Y, Nakamura K, Uchida T and Sugie T (1987) Full term development of mouse blastomere transplanted into enucleated twocell embryos journal of Experimental Zoology 242 147-151

Von Beroldingen $\mathrm{CH}$ (1981) The developmental potential of synchronized amphibian cell nuclei Developmental Biology 81 115-126

Whittingham DG (1971) Culture of mouse ova Joumal of Reproduction and Fertility 14 7-12 